\title{
Assessment of Perianesthesic Data in Subjects Undergoing Endobronchial Ultrasound-Guided Transbronchial Needle Aspiration
}

\author{
Hilal Sazak MD, Mehtap Tunç MD, Ali Alagöz MD, Polat Pehlivanoğlu MD, \\ Nilgün Yılmaz Demirci MD, İbrahim O Alıcı MD, and Aydın Yılmaz MD
}

\begin{abstract}
BACKGROUND: Transbronchial needle aspiration using endobronchial ultrasonography (EBUSTBNA), a new minimally invasive diagnostic procedure, has been used to evaluate intrathoracic lymph nodes. It has been reported that EBUS-TBNA can be performed safely under sedation and provides a high level of patient satisfaction. We aimed to describe perianesthetic data, and compare results regarding the agents of subjects undergoing EBUS-TBNA under deep sedation. METHODS: After ethics committee approval, perianesthetic data of 571 subjects undergoing EBUS-TBNA were analyzed retrospectively. Data were collected from anesthesia evaluation and observation forms. Four groups received anesthesia in the operating room as follows: propofol-midazolam (group PM), propofol-ketamine (group PK), propofol-ketamine-midazolam (group PKM), or propofol (group P). Dosage, number of anesthetic injection, hemodynamic variables, recovery time, complications, and patient satisfaction were also recorded. RESULTS: Propofol consumption was higher in groups $\mathbf{P}$ and PM compared with groups PK and PKM. Midazolam requirement was higher in group PM than in group PKM. Recovery time was shorter in group P compared with groups PK, PM, and PKM. It was also shorter in groups PK and PM compared with group PKM. All of these differences were statistically significant. Temporary desaturation $(n=41 ; 7 \%)$ and increased blood pressure ( $n=78 ; 14 \%)$ were predominant complications. In groups PK and PKM, risk of developing hypertension was higher than in groups $P M$ and $P(P<.001)$. The percentage of subjects satisfied with the procedure was $99 \%$. CONCLUSIONS: Independent from the sedative agent, deep sedation can be safe, and provide high patient satisfaction during EBUS-TBNA. The combination of ketamine with propofol or midazolam required lower doses of these anesthetics. However, the incidence of increased blood pressure was higher in groups administered ketamine. Recovery time was the shortest in group $\mathrm{P}$, and the longest in group PKM. There was no relation between recovery time and total dose of anesthetics or presence of chronic disease. Key words: endobronchial ultrasoundguided transbronchial needle aspiration; sedation; propofol; ketamine; midazolam. [Respir Care 2015;60(4):567-576. ㅇ 2015 Daedalus Enterprises]
\end{abstract}

\section{Introduction}

Endobronchial ultrasonography (EBUS) is a bronchoscopic method developed to image structures on the air-

\footnotetext{
Drs Sazak, Tunç, Alagöz, and Pehlivanoğlu are affiliated with the Department of Anesthesiology and Reanimation, Ataturk Chest Diseases and Thoracic Surgery Education and Research Hospital, Ankara, Turkey; Drs Demirci, Alıc1, and Yilmaz are affiliated with the Department of Chest Diseases and Tuberculosis, Ataturk Chest Diseases and Thoracic Surgery Education and Research Hospital, Ankara, Turkey.
}

This research was presented in poster form at the 16th Annual Congress of Turkish Thoracic Society, held April 3-7, 2013, in Antalya, Turkey. way walls or neighboring airways. There are 2 types of EBUS: radial EBUS and linear EBUS (convex probe EBUS). Whereas convex probe EBUS provides sametime sampling, sequential sampling is made with radial

\footnotetext{
The authors have disclosed no conflicts of interest.

Correspondence: Hilal Sazak MD, Department of Anesthesiology and Reanimation, Ataturk Chest Diseases and Thoracic Surgery Education and Research Hospital, Keciören, Ankara 06280, Turkey. E-mail: hilalgun@yahoo.com.
}

DOI: $10.4187 /$ respcare.03547 
EBUS. Both techniques increase the diagnostic value of blind transbronchial needle aspiration (TBNA). ${ }^{1}$ Mediastinoscopy is the accepted standard for invasive mediastinal staging for lung cancer. However, mediastinoscopy requires general anesthesia because it is an invasive method. ${ }^{2}$ EBUS is minimally invasive, and it can be performed as an out-patient procedure using local anesthesia and conscious sedation. Sampling can be made through lymph node stations. The most frequent indications for EBUS are diagnosis and staging of lung cancer and diagnosis of mediastinal lesions. Systemic reviews and meta-analysis showed that EBUS is a safe, sensitive, and specific procedure. Yasufuku et $\mathrm{al}^{3}$ compared 2 techniques, EBUS-TBNA and mediastinoscopy, for mediastinal staging in patients with resectable, small cell lung cancer and found that both techniques are $100 \%$ specific and have $100 \%$ positive predictivity value. For mediastinal lymph node staging, the values for sensitivity, negative predictivity value, and diagnostic accuracy for EBUS-TBNA and mediastinoscopy were $81 \%, 91 \%, 93 \%$, and $79 \%, 90 \%$, and $93 \%$, respectively. Results of a meta-analysis that includes 1,299 patients from 11 studies that used EBUS for mediastinal staging showed that sensitivity was 93\% (range 91-94\%) and specificity was $100 \% .^{4}$

It has been proposed that EBUS-TBNA can be performed safely with high patient satisfaction under conscious sedation. In one study, which used midazolam, fentanyl, and/or propofol, high patient satisfaction was found independent from the sedation protocol. ${ }^{5}$ Benzodiazepines, propofol, opioids, and ketamine are used by themselves or in a combination for sedation for bronchoscopic procedures. ${ }^{6-8}$ However, the opioid-benzodiazepine combination has a long-lasting effect and causes respiratory depression, as well as prolonged sedation. ${ }^{9}$ Propofol, a sedative and hypnotic, has a fast-acting effect and short recovery time, but it also has disadvantages like cardiovascular and respiratory depression. ${ }^{10,11}$ Ketamine, a dissociative, sedative, analgesic, and amnesic agent, has been suggested as an optimal agent especially for bronchoscopic sedation because of its high cardiac and respiratory profile. ${ }^{8}$ However, ketamine has some side effects, such as increased secretion, vomiting, and nausea, as well as prolonged effect. ${ }^{9}$ For all these reasons, an ideal sedative agent or combination for bronchoscopic procedures in particular has not yet been suggested.

Although studies investigating the ketamine-propofol combination for sedation for emergency room procedures are common, ${ }^{12-15}$ to our knowledge, studies investigating sedative agents (especially ketamine-propofol combination) for EBUS are limited. This combination is preferred, as the agents have opposite respiratory and hemodynamic effects. ${ }^{13}$ Recently, in a prospective trial including 60 subjects undergoing EBUS-TBNA, Dal et al ${ }^{16}$ concluded that

\section{QUICK LOOK}

\section{Current knowledge}

Transbronchial needle aspiration using endobronchial ultrasonography, a minimally invasive diagnostic procedure, has been used to evaluate intrathoracic lymph nodes. It has been reported that this technique can be performed safely under sedation and provides a high level of patient satisfaction.

\section{What this paper contributes to our knowledge}

Independent from the sedative agent, deep sedation provided a high level of patient satisfaction, hemodynamic and respiratory stability, and faster recovery time in subjects undergoing transbronchial needle aspiration. There was no relationship between the presence of complications and age, presence of comorbidities, procedure time, and the number of sedatives delivered. The incidence of developing high blood pressure was higher in groups receiving ketamine.

ketamine's combination with either midazolam or propofol provided good levels of satisfaction for the subjects and the bronchoscopist without remarkable side effects.

In this retrospective study, we aimed to identify demographic, clinical, hemodynamic, and respiratory data along with sedative doses, procedure duration, and complications in subjects undergoing EBUS-TBNA under sedation. We also sought to compare all data with respect to sedation groups.

\section{Methods}

After approval by the institutional ethics committee, data were collected retrospectively. We analyzed the perianesthetic data for 571 sedated subjects who underwent EBUS-TBNA for diagnosis and staging in a 13-month period. Data were collected from the forms that were filled during the preanesthetic evaluation, during anesthesia, and during the postanesthetic observation.

Previously recorded demographic features, results of pulmonary function tests (PFTs), presence of any chronic disease (diabetes mellitus, hypertension, coronary artery disease, COPD, asthma, or tuberculosis), and physical status according to the American Society of Anesthesiologists (ASA) were evaluated. Moreover, duration of EBUSTBNA, sedation agent and dosages, number of repeated injections, recovery time, patient satisfaction score, and complications (bleeding, pneumothorax, increased or decreased blood pressure, bradycardia, desaturation, and allergy) were also assessed. 
Before sedation (baseline values), after induction (first measurement), after the fiberoptic bronchoscope passed the vocal cords (second measurement), and every $3 \mathrm{~min}$ during the procedure, systolic arterial pressure, diastolic arterial pressure, mean arterial pressure, heart rate (HR), and $\mathrm{S}_{\mathrm{pO}_{2}}$ were recorded. Patient satisfaction was scored using the following question: "Would you undergo another EBUS-TBNA under sedation?" Answers were scored as follows: "absolutely no" (score 1); "no, I wouldn't (score 2); "I am in doubt" (score 3); "yes, I would" (score 4); "absolutely yes" (score 5) $4 \mathrm{~h}$ after completion of procedure.

Electrocardiogram, blood pressures, and $\mathrm{S}_{\mathrm{pO}_{2}}$ were monitored in the operating room. An intravenous catheter was inserted for saline infusion and injections. During the procedure, $4 \mathrm{~L} / \mathrm{min}$ oxygen was given via a nasal cannula. There were 4 groups: propofol-midazolam (group PM), propofol-ketamine (group PK), propofol-ketaminemidazolam (group PKM), and propofol only (group P). A sedation protocol accepted by our department for EBUS patients had been applied under the supervision of specialists using the following agents: propofol (Fresenius Kabi AB, Uppsala, Sweden), ketamine (Ketalar, Pfizer, Zentiva, Lüleburgaz, Turkey), or/and midazolam (Demizolam, Dem, Turkey).

Sedation level had been adjusted to a Ramsay Sedation Scale score of 4-5 in all subjects. At level 4 , the subject is sleeping, but he/she responds quickly to light physical stimulation or voice; at level 5, the subject is sleeping, but he/she responds slowly to light physical stimulation or voice. ${ }^{17}$ After adequate sedation was provided, a fiberoptic bronchoscope was allowed to pass the vocal cords. During the procedure, if the Ramsay Sedation Scale score was under 4, the anesthetic agent was repeated. Lidocaine (2\%) was sprayed to the airways during bronchoscopy. Biopsies were taken by evaluating bronchoscopic observation. All of the EBUS-TBNA procedures were performed by the same bronchoscopy team. At the end of the procedure, recovery time was established as the time between the removal of bronchoscope from the vocal cords and the achievement of a modified Aldrete score of $9^{18}$ in the recovery room, at which point subjects were sent to the ward. If $\mathrm{S}_{\mathrm{pO}_{2}}$ was $<90 \%$ for $>1$ min during sedation, it was recorded as desaturation, and oxygen was increased to $6 \mathrm{~L} / \mathrm{min}$. Any need for mask ventilation or endotracheal intubation (within $24 \mathrm{~h}$ after bronchoscopy) was noted. In case of $\mathrm{HR}<50$ beats/min and atropine injection, bradycardia was written down. A $20 \%$ increase or decrease in systolic arterial pressure compared with baseline values and nitroglycerine or ephedrine was recorded as high blood pressure or low blood pressure, respectively. Steroids and antihistamines were administered if an allergic reaction developed during sedation.

\section{Statistical Analysis}

All data were analyzed using SPSS 11.5 (SPSS, Chicago, Illinois). To determine whether variables were normally distributed, we used the Kolmogorov-Smirnov test, and to determine homogeneity of variance, we used the Levene test. Variable data were shown as mean \pm SD or as median, and categorized data were expressed as number and percent. We used the Student $t$ test to compare 2 groups and one-way variance analysis to compare more than 2 groups. When we compared median values, the Kruskal-Wallis test was used for 2-group comparison and a Mann-Whitney U test was used for comparison of $>2$ groups. According to one-way variance analysis and Kruskal-Wallis test results, the Tukey honest significant difference test or Conover non-parametric multiple comparison tests were used post hoc to determine the groups causing statistical difference. Categorized variances were analyzed using a Pearson chi-square or Fisher exact chisquare. To determine statistically meaningful correlation among variables, we used the Spearman correlation test.

Effects of absolute and possible risk factors on development of complications were analyzed using multiple variable logistic regression analysis. For single-variable analysis, variables for which $P<.10$ were included in regression analysis as possible risk factors. In addition, odds ratio and $95 \%$ CI were calculated for every variable.

$P<.05$ was accepted as statistically significant. However, to prevent a type 1 error, the Bonferroni correction was applied for multiple comparisons.

\section{Results}

Table 1 summarizes demographic features, ASA classification, presence of underlying disease, pulmonary function tests, complications, duration of EBUS procedure, recovery time, and patient satisfaction scores. Before the procedure, the mean value of $\mathrm{FEV}_{1}$ was $77.9 \pm 20.02 \%$, $\mathrm{FVC}$ was $80.22 \pm 19.29 \%$, and $\mathrm{FEV}_{1} / \mathrm{FVC}$ was $79.23 \pm 8.58 \%$. Mean duration of EBUS-TBNA and recovery were $16.19 \pm 5.1 \mathrm{~min}$ and $15.67 \pm 3.77 \mathrm{~min}$, respectively. Answers for the question "Would you have another EBUS-TBNA procedure under sedation?" were as follows: 457 subjects (80\%) answered as "absolutely yes"; 108 subjects (19\%) answered as "yes, I would"; 2 subjects $(<1 \%)$ answered as "I am in doubt"; $2(<1 \%)$ subjects answered as "no, I wouldn't"; and 2 subjects $(<1 \%)$ answered as "absolutely no."

Table 2 shows detailed demographic and clinical data for each anesthetic group. There were significant statistical differences among groups regarding average age, gender, ASA classification, underlying diseases (such as diabetes mellitus, hypertension, and coronary artery disease), re- 
Table 1. Description of Demographic and Clinical Features of the Subjects

\begin{tabular}{lc}
\hline \hline & Variables \\
\hline Subjects $(N)$ & 571 \\
Age $(\mathrm{y})$ & $55.7 \pm 13.5$ \\
Gender, $n(\%)$ & \\
$\quad$ Male & $386(68)$ \\
$\quad$ Female & $185(32)$ \\
Body weight $(\mathrm{kg})$ & $74.5 \pm 14.1$ \\
Body mass index $\left(\mathrm{kg} / \mathrm{m}^{2}\right)$ & $26.6 \pm 5.0$ \\
ASA classification & $2(1-4)$ \\
I, $n(\%)$ & $28(5)$ \\
II, $n(\%)$ & $263(46)$ \\
III, $n(\%)$ & $272(48)$ \\
IV, $n(\%)$ & $8(1)$ \\
Comorbidity & $386(68)$ \\
FEV $1 \%$ & $80(23-169)$ \\
FVC $\%$ & $80(22-147)$ \\
FEV $/$ /FVC $\%$ & $79(47-101)$ \\
Complication, $n(\%)$ & $118(21)$ \\
Duration of EBUS (min) & $15(10-35)$ \\
Recovery time (min) & $16(9-29)$ \\
Patient satisfaction score & $5(1-5)$ \\
& \\
\hline Data are given as mean \pm SD, $n(\%)$, or median (range). & \\
ASA = American Society of Anesthesiology & \\
EBUS = endobronchial ultrasonography & \\
\hline
\end{tabular}

covery time, and patient satisfaction $(P<.05)$. To determine the cause of statistical difference for these parameters, binary comparisons among groups were performed, and average age was significantly lower in groups $\mathrm{PK}$ and PKM than in group $\mathrm{P}(P=.006, P=.03)$. Group PK had statistically more male subjects than in group PKM. ASA III subjects in group PK (38\%) were statistically lower than in group P $(63 \%)$ and group PM $(56 \%)(P=.004$, $P=.002)$. Underlying disease was significantly less frequent in group PK compared with groups $\mathrm{P}$ and $\mathrm{PM}$. The frequency of diabetes mellitus was less in group PK than in other groups. The percentage of hypertension in group PK was significantly lower than in groups $\mathrm{P}$ and PM, and this value in group PKM was also less than in group P. The frequency of coronary artery disease in groups PK and PKM was statistically lower than in group PM.

Recovery time was $13.42 \pm 2.94 \mathrm{~min}$ in group $\mathrm{P}$, and it was significantly lower than in groups PK (15.46 \pm $3.52 \mathrm{~min}), \mathrm{PM}(15.91 \pm 3.81 \mathrm{~min})$, and PKM (17.05 $\pm 3.96 \mathrm{~min})$. Recovery times in groups PK and PM were statistically shorter than in group PKM. Times were similar in groups PK and PM $(P>.05)$. There was statistically significant inverse correlation between recovery time and age $(\mathrm{r}=-0.097$ and $P=.02)$, and direct correlation among EBUS-TBNA time $(\mathrm{r}=0.103$ and $P=.01)$, beginning mean arterial pressure $(\mathrm{r}=0.085$ and $P=.04)$, and beginning HR $(\mathrm{r}=0.094$ and $P=.03)$. There was no correlation between recovery time and gender, ASA classification, PFTs, total anesthetic doses, and presence of comorbidity $(P>.05)$.

The percentage of subjects who answered "yes, I would absolutely have another EBUS-TBNA under sedation" was $72 \%$ in group PKM and $86 \%$ in group PM. Although the percentage of subjects who answered "yes, I would" was $23 \%$ in group PKM, it was $14 \%$ in group PM. This difference was statistically meaningful; however, it was not in clinical practice. Patient satisfaction rates according to groups are shown in Figure 1. Other demographic and clinical features were similar among groups $(P>.05)$.

The mean propofol dose used in induction was $41.05 \pm$ $14.87 \mathrm{mg}$ in group PM, $26.47 \pm 9.61 \mathrm{mg}$ in group $\mathrm{PK}$, $24.08 \pm 8.22 \mathrm{mg}$ in group PKM, and $47.08 \pm 13.41 \mathrm{mg}$ in group P. Total doses of agents and the number of intravenous injections for every group are displayed in Table 3. To determine the origin of statistical difference for total propofol and midazolam, binary comparisons were performed. Total propofol dosage was statistically higher in groups $\mathrm{P}(108.67 \pm 54.89 \mathrm{mg})$ and $\mathrm{PM}(98.14 \pm 60.35 \mathrm{mg})$ than in groups PK $(56.18 \pm 28.13 \mathrm{mg})$ and PKM $(55.92 \pm 29.69 \mathrm{mg})$. The higher midazolam dose in group PM $(2.33 \pm 1.14 \mathrm{mg})$ was statistically significantly compared to group PKM $(2 \pm 0.84 \mathrm{mg})(P<.001)$. Average number of anesthetic injections was $2.42 \pm 1.43$ for all subjects.

Table 4 exhibits hemodynamic and $\mathrm{S}_{\mathrm{pO}_{2}}$ values for every group. There was significant difference among groups for systolic arterial pressure, diastolic arterial pressure, and mean arterial pressure values on the second, third, fourth, and fifth measurements taken at the beginning and continuation of the bronchoscopy $(P<.001)$. To determine the origin of statistical difference, binary group comparisons were made. The second measurement of systolic arterial pressure was higher in group PKM than in group P. The third measurement of systolic arterial pressure was also higher in group PK than in group P. The fourth and fifth measurements of systolic arterial pressure were similar in groups PK and PKM, as well as higher than in groups $\mathrm{P}$ and PM. The second measurement of diastolic arterial pressure was higher in group PKM than in group PM. The third, fourth, and fifth measurements of diastolic arterial pressure and mean arterial pressure were similar in groups PK and PKM, and they were higher than in group PM. The second measurement of mean arterial pressure was higher in group PKM than in groups P and PM.

A total of $118(21 \%)$ subjects suffered from at least one complication during the procedure. Table 5 presents the complications defined in all groups. Some subjects had more than one complication. There was no correlation between occurrence of complication and age, ASA classification, PFTs, comorbidity, EBUS-TBNA duration, and the number of anesthetic injections $(P>.05)$. There was 


\section{SEdATION In ENDOBRonchial Ultrasound-Guided TBNA}

Table 2. Distribution of Demographic and Clinical Data According to Groups

\begin{tabular}{|c|c|c|c|c|c|}
\hline Variables & $\begin{array}{l}\text { Group PM } \\
(n=174)\end{array}$ & $\begin{array}{l}\text { Group PK } \\
(n=234)\end{array}$ & $\begin{array}{l}\text { Group PKM } \\
(n=103)\end{array}$ & $\begin{array}{l}\text { Group P } \\
(n=60)\end{array}$ & $P$ \\
\hline Age $(y)$ & $57.2 \pm 12.6$ & $53.9 \pm 13.9^{*}$ & $54.3 \pm 13.8 \dagger$ & $60.3 \pm 12.5^{* \dagger}$ & .002 \\
\hline Gender, $n(\%)$ & & & & & .048 \\
\hline Male & $110(63)$ & $169(72) \ddagger$ & $62(60) \ddagger$ & $45(75)$ & \\
\hline Female & $64(37)$ & $65(28) \div$ & $41(40) \div$ & $15(25)$ & \\
\hline Body weight $(\mathrm{kg})$ & $75.2 \pm 14.0$ & $74.1 \pm 13.6$ & $73.7 \pm 12.7$ & $75.4 \pm 18.0$ & .78 \\
\hline Body mass index $\left(\mathrm{kg} / \mathrm{m}^{2}\right)$ & $26.7 \pm 4.7$ & $26.3 \pm 4.9$ & $26.9 \pm 4.8$ & $27.2 \pm 6.1$ & .64 \\
\hline ASA classification & $3(1-4) \S$ & $2(1-4) * \S$ & $2(1-4)$ & $3(1-3)^{*}$ & $<.001$ \\
\hline Comorbidity, $n(\%)$ & $127(73) \S$ & $140(60) * \S$ & $70(68)$ & $49(82)^{*}$ & .003 \\
\hline $\mathrm{DM}$ & $34(20) \S$ & $26(11) * \$ \S$ & $21(20) \ddagger$ & $16(27)^{*}$ & .01 \\
\hline Hypertension & $61(35) \S$ & $49(21) * \S$ & $30(29) \dagger$ & $27(45.0)^{*} \dagger$ & $<.001$ \\
\hline CAD & $40(23) \S \|$ & $17(7) \S$ & $12(12) \|$ & $7(12)$ & $<.001$ \\
\hline COPD & $17(10)$ & $27(12)$ & $6(6)$ & $4(7)$ & .34 \\
\hline Asthma & $9(5)$ & $14(6.0)$ & $10(10)$ & $1(2)$ & .19 \\
\hline Tuberculosis & $4(2)$ & $6(3)$ & $3(3)$ & $1(2)$ & .96 \\
\hline $\mathrm{FEV}_{1} \%$ & $78.5(23-142)$ & $82(27-169)$ & $80(29-120)$ & $80(27-130)$ & .50 \\
\hline FVC $\%$ & $78.5(22-133)$ & $83(25-147)$ & $79(31-126)$ & $79(33-147)$ & .09 \\
\hline $\mathrm{FEV}_{1} / \mathrm{FVC} \%$ & $80(53-100)$ & $79(47-101)$ & $78(62-96)$ & 79 (56-99) & .56 \\
\hline Duration of EBUS (min) & $15(10-30)$ & $15(10-35)$ & $15(10-35)$ & $15(10-35)$ & .12 \\
\hline Recovery time (min) & $16(9-25) \| \mathscr{| \Psi}$ & $16(9-28)^{*}+$ & $17(10-29) \dagger \dagger \|$ & $13(9-21)^{*}+$ पI & $<.001$ \\
\hline Patient satisfaction score & $5(4-5) \|$ & $5(2-5)$ & $5(1-5) \|$ & $5(4-5)$ & .03 \\
\hline $\begin{array}{l}\text { Data are given as mean } \pm \text { SD, } n \text { (\% } \\
\text { * Statistically significant difference } \\
\text { † Statistically significant difference } \\
\text { ₹ Statistically significant difference } \\
\text { \& Statistically significant difference } \\
\| \text { Statistically significant difference } \\
\text { II Statistically significant difference } \\
\text { Group PM = propofol-midazolam } \\
\text { Group PK = propofol-ketamine } \\
\text { Group PKM = propofol-ketamine-n } \\
\text { Group P = propofol } \\
\text { ASA = American Society of Anestl } \\
\text { DM }=\text { diabetes mellitus } \\
\text { CAD = coronary artery disease } \\
\text { EBUS }=\text { endobronchial ultrasonogr }\end{array}$ & $\begin{array}{l}\text { (range). Percentage to } \\
\text { up PK and group P ( } P \\
\text { up PKM and group P } \\
\text { up PK and group PKN } \\
\text { up PM and group PK } \\
\text { ip PM and group PKN } \\
\text { up PM and group P ( }\end{array}$ & er from $100 \%$ becau & & & \\
\hline
\end{tabular}

a 4.923-fold increase in the possibility of complications in group PK (95\% CI 1.653-14.659, $P=.004)$ and 3.497fold increase in group PKM (95\% CI 1.032-11.853, $P=.044)$ compared with group $\mathrm{P}$.

There were statistically more complications in group PK compared with group PM $(P<.05)$. We found significant differences between groups regarding increased blood pressures $(P<.001)$. High blood pressure was more frequent in groups PK and PKM than in group PM $(P<.05)$. One subject who developed a pneumothorax during EBUS-TBNA was admitted to the ICU with desaturation. A chest tube was placed uneventfully after endotracheal intubation. Another subject with mediastinal fibrosis was intubated because of bleeding due to EBUSTBNA. Although one subject (in group PM) developed desaturation and was ventilated with a face mask, 4 subjects ( 2 in group PM, and 2 in group PKM) required endotracheal intubation. Only one with a pneumothorax needed mechanical ventilation.
The majority of subjects with high blood pressure as a complication were female $(P=.02)$. The subjects with elevated blood pressure had statistically higher baseline arterial pressures $(P<.001)$. In addition, subjects who had previously diagnosed hypertension had a higher risk of developing high blood pressure during the procedure (odds ratio $1.883,95 \%$ CI $1.049-3.381$, and $P=.034$ ).

Groups PK and PKM had a higher risk of developing high blood pressure compared with groups $\mathrm{PM}$ and $\mathrm{P}$ $(P<.001)$. According to the multiple variable regression analysis, baseline systolic arterial pressure level was the most significant factor associated with developing high blood pressure $(P<.001)$. Probability of developing high blood pressure was 4.602 times higher in group PK than in group P (95\% CI 1.547-13.693, $P=.006)$.

Subjects with desaturation were mainly female $(P=.048)$. Baseline $\mathrm{FEV}_{1}, \mathrm{FVC}$, and $\mathrm{FEV}_{1} / \mathrm{FVC}$ values were statistically lower in subjects with desaturation $(P<.05)$. Their mean PFT results were as follows: 


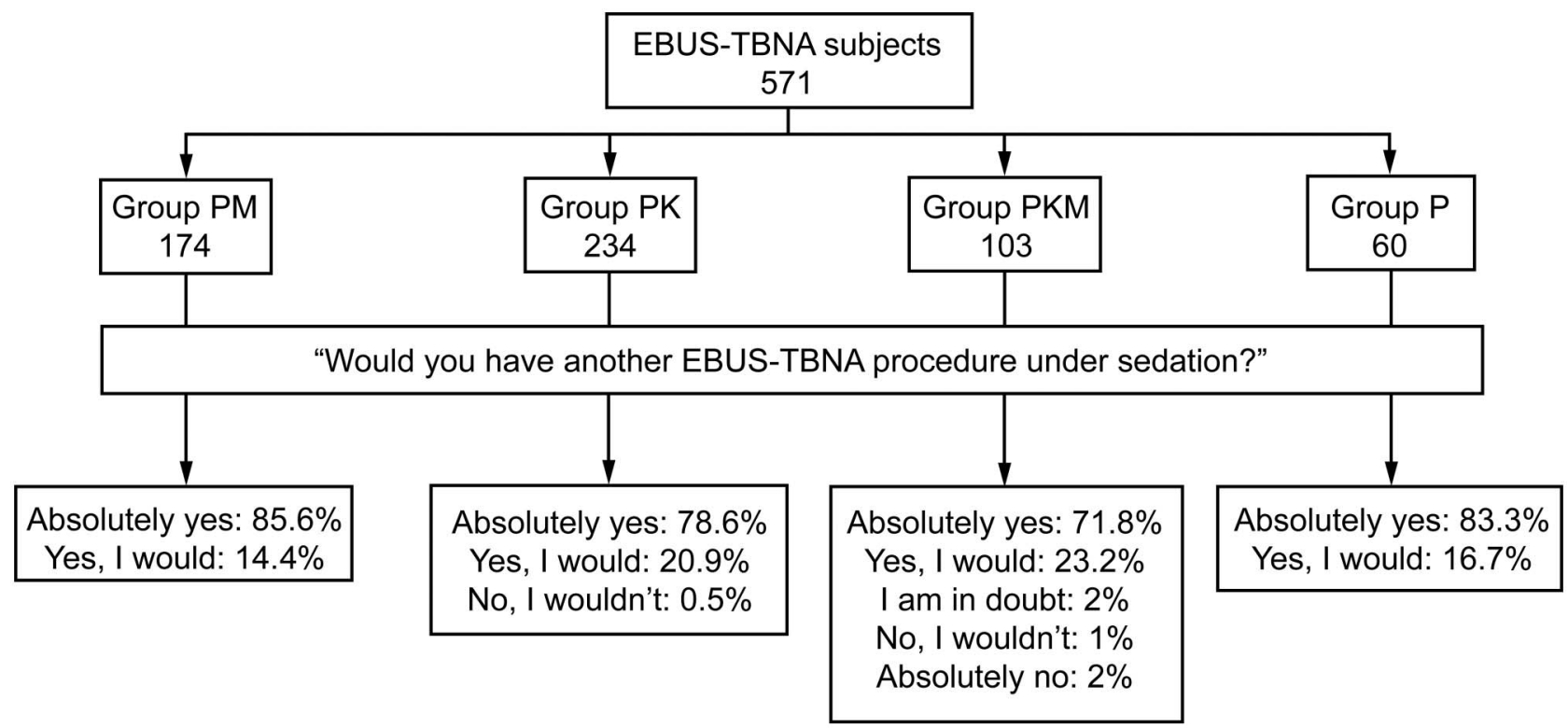

Fig. 1. Flow chart. EBUS-TBNA = endobronchial ultrasound-guided transbronchial needle aspiration; group PM = propofol-midazolam; group PK = propofol-ketamine; group PKM = propofol-ketamine-midazolam; group P = propofol.

Table 3. Medication Requirements in the Groups

\begin{tabular}{|c|c|c|c|c|c|}
\hline Variables & $\begin{array}{c}\text { Group PM } \\
(n=174)\end{array}$ & $\begin{array}{l}\text { Group PK } \\
(n=234)\end{array}$ & $\begin{array}{c}\text { Group PKM } \\
(n=103)\end{array}$ & $\begin{array}{l}\text { Group P } \\
(n=60)\end{array}$ & $P$ \\
\hline Total profopol (mg) & $87.5(20-400) * \dagger$ & $50(15-220)^{*} \ddagger$ & $50(15-190) \dagger \S$ & $100(30-250) \ddagger \S$ & $<.001$ \\
\hline Total ketamine (mg) & NA & $50(10-135)$ & $40(10-120)$ & NA & .13 \\
\hline Total midazolam (mg) & $2(1-10) \|$ & NA & $2(1-5)$ & NA & $<.001$ \\
\hline Count of agent repetition & $2(1-9)$ & $2(1-8)$ & $2(1-8)$ & $2.5(1-8)$ & .17 \\
\hline $\begin{array}{l}\text { Data are given as median (range). } \\
\text { * Statistically significant differenc } \\
\text { † Statistically significant differenc } \\
\text { ₹ Statistically significant differenc } \\
\text { \& Statistically significant differenc } \\
\| \text { Statistically significant differenc } \\
\text { Group PM = propofol-midazolam } \\
\text { Group PK = propofol-ketamine } \\
\text { Group PKM = propofol-ketamine- } \\
\text { Group P = propofol } \\
\text { NA = not applicable }\end{array}$ & $\begin{array}{l}\text { roup PM and group PK } \\
\text { roup PM and group PKM } \\
\text { roup PK and group P } P \\
\text { roup PKM and group P } \\
\text { oup PM and group P ( } P\end{array}$ & & & & \\
\hline
\end{tabular}

$\mathrm{FEV}_{1}$ of $68.81 \pm 18.83 \%, \mathrm{FVC}$ of $72.56 \pm 18.64 \%$, and $\mathrm{FEV}_{1} / \mathrm{FVC}$ of $75.97 \pm 5.81$. Beginning $\mathrm{S}_{\mathrm{pO}_{2}}$ was also lower in subjects with desaturation $(94.56 \pm 2.57 \%)$ compared with all subjects $(96.29 \pm 2.25 \%)(P<.001)$. Logistic regression analysis showed that only baseline $\mathrm{S}_{\mathrm{pO}_{2}}$ was associated with developing desaturation (odds ratio $0.719,95 \%$ CI $0.597-0.865, P<.01)$.

\section{Discussion}

Our results show that propofol by itself or in combination with midazolam and/or ketamine provides high patient satisfaction, hemodynamic and respiratory stability, fast recovery, and effective as well as safe sedation for EBUS-TBNA. We observed that using a combination with ketamine decreases the requirement for propofol and midazolam. Development of high blood pressure during the procedure was higher in groups with ketamine. Recovery time was the lowest in group $\mathrm{P}$ and the highest in group PKM.

EBUS-TBNA is a very safe and highly recommended procedure to diagnose malignant or non-malignant mediastinal and hilar lymphadenopathy. ${ }^{19}$ Studies have shown that EBUS-TBNA requires more sedation than TBNA. ${ }^{19,20}$ Yarmus et $\mathrm{al}^{21}$ reported that diagnostic success and the 


\section{SEdATION In ENDOBRonchial Ultrasound-Guided TBNA}

Table 4. Hemodynamic Data and $\mathrm{S}_{\mathrm{pO}_{2}}$ Measurements in the Groups

\begin{tabular}{|c|c|c|c|c|c|}
\hline Variables & $\begin{array}{c}\text { Group PM } \\
(n=174)\end{array}$ & $\begin{array}{l}\text { Group PK } \\
(n=234)\end{array}$ & $\begin{array}{c}\text { Group PKM } \\
(n=103)\end{array}$ & $\begin{array}{l}\text { Group P } \\
(n=60)\end{array}$ & $P^{*}$ \\
\hline \multicolumn{6}{|c|}{ Mean arterial pressure $(\mathrm{mm} \mathrm{Hg})$} \\
\hline Baseline values & $91.7 \pm 12.7$ & $91.5 \pm 12.0$ & $94.5 \pm 12.0$ & $91.5 \pm 12.9$ & .19 \\
\hline First measurement & $92.9 \pm 14.2$ & $92.8 \pm 12.6$ & $95.4 \pm 10.8$ & $89.4 \pm 13.1$ & .07 \\
\hline Second measurement & $91.8 \pm 15.9 \|$ & $95.8 \pm 14.1$ & $98.6 \pm 12.5 \dagger \|$ & $90.1 \pm 14.3 \dagger$ & $<.001$ \\
\hline Third measurement & $90.9 \pm 15.6 \S \|$ & $97.1 \pm 14.2 \S$ & $97.7 \pm 14.5 \|$ & $90.3 \pm 14.9$ & $<.001$ \\
\hline Fourth measurement & $90.0 \pm 15.8 \S \|$ & $97.3 \pm 13.5 \S$ & $98.5 \pm 13.2 \|$ & $90.5 \pm 14.6$ & $<.001$ \\
\hline Fifth measurement & $89.5 \pm 15.5 \S \|$ & $97.1 \pm 12.9 \S$ & $97.8 \pm 11.9 \|$ & $90.7 \pm 15.5$ & $<.001$ \\
\hline \multicolumn{6}{|l|}{ Heart rate (beats/min) } \\
\hline Baseline values & $82.7 \pm 13.6$ & $83.9 \pm 12.2$ & $86.4 \pm 12.8$ & $82.0 \pm 13.7$ & .10 \\
\hline First measurement & $84.3 \pm 14.1$ & $86.0 \pm 13.1$ & $88.2 \pm 12.4$ & $83.5 \pm 12.5$ & .11 \\
\hline Second measurement & $85.3 \pm 14.5$ & $86.9 \pm 13.1$ & $89.5 \pm 12.5$ & $84.9 \pm 13.0$ & .10 \\
\hline Third measurement & $86.2 \pm 13.7$ & $87.4 \pm 13.7$ & $90.0 \pm 13.0$ & $85.0 \pm 11.8$ & .12 \\
\hline Fourth measurement & $86.3 \pm 14.0$ & $88.0 \pm 13.9$ & $90.4 \pm 13.4$ & $84.6 \pm 12.2$ & .06 \\
\hline Fifth measurement & $86.3 \pm 13.5$ & $88.6 \pm 13.7$ & $91.3 \pm 13.0$ & $84.7 \pm 11.5$ & .01 \\
\hline \multicolumn{6}{|l|}{$\mathrm{S}_{\mathrm{pO}_{2}}(\%)$} \\
\hline Baseline values & $95.7 \pm 2.7 \S \|$ & $96.5 \pm 2.0 \S$ & $96.7 \pm 1.9 \|$ & $96.4 \pm 1.9$ & .003 \\
\hline First measurement & $96.2 \pm 2.6$ & $96.5 \pm 2.3$ & $96.0 \pm 6.0$ & $95.9 \pm 2.2$ & .51 \\
\hline Second measurement & $95.9 \pm 3.1$ & $96.1 \pm 2.7$ & $95.9 \pm 4.3$ & $95.4 \pm 2.6$ & .68 \\
\hline Third measurement & $95.5 \pm 3.1$ & $95.8 \pm 3.0$ & $96.4 \pm 2.3$ & $95.6 \pm 2.2$ & .17 \\
\hline Fourth measurement & $95.2 \pm 4.0$ & $95.9 \pm 3.2$ & $96.3 \pm 2.2$ & $95.6 \pm 2.7$ & .13 \\
\hline Fifth measurement & $95.6 \pm 3.2$ & $96.2 \pm 3.3$ & $96.4 \pm 2.1$ & $95.9 \pm 2.8$ & .28 \\
\hline \multicolumn{6}{|c|}{$\begin{array}{l}\text { Data are given as mean } \pm \text { SD. } \\
\text { * Results were statistically significant with Bonferroni correction }(P<.008) \text {. } \\
\dagger \text { Statistically significant difference between group PKM and group P }(P<.008) \text {. } \\
\text { \& Statistically significant difference between group PM and group PK }(P<.008) \text {. } \\
\| \text { Statistically significant difference between group PM and group PKM }(P<.008) \text {. } \\
\text { Group PM = propofol-midazolam } \\
\text { Group PK = propofol-ketamine } \\
\text { Group PKM = propofol-ketamine-midazolam } \\
\text { Group P = propofol }\end{array}$} \\
\hline
\end{tabular}

Table 5. Summary of Intraprocedural Complications in the Groups

\begin{tabular}{|c|c|c|c|c|c|}
\hline Variables & $\begin{array}{c}\text { Group PM } \\
(n=174)\end{array}$ & $\begin{array}{l}\text { Group PK } \\
(n=234)\end{array}$ & $\begin{array}{c}\text { Group PKM } \\
(n=103)\end{array}$ & $\begin{array}{l}\text { Group P } \\
(n=60)\end{array}$ & $P$ \\
\hline Complication & $26(15)^{*}$ & $59(25)^{*}$ & $24(23)$ & $9(15)$ & .045 \\
\hline Bleeding & NA & $1(1)$ & NA & NA & NA \\
\hline Pneumothorax & $1(0.6)$ & NA & NA & NA & NA \\
\hline High blood pressure & $10(6)^{* \dagger}$ & $45(19)^{*}$ & $17(17) \dagger$ & $6(10)$ & $<.001$ \\
\hline Low blood pressure & NA & NA & $1(1)$ & NA & NA \\
\hline Bradycardia & $1(1)$ & NA & $1(1)$ & NA & NA \\
\hline Allergy & $1(1)$ & $5(2)$ & NA & NA & .12 \\
\hline Desaturation & $20(12)$ & $12(5)$ & $6(6)$ & $3(5)$ & .07 \\
\hline $\begin{array}{l}\text { Data are given as } n(\%) \text {. Percen } \\
* \text { Statistically significant differe } \\
\dagger \text { Statistically significant differe } \\
\text { Group PM = propofol-midazola } \\
\text { Group PK = propofol-ketamine } \\
\text { Group PKM = propofol-ketami } \\
\text { Group P = propofol } \\
\mathrm{NA}=\text { not applicable }\end{array}$ & $\begin{array}{l}\text { ffer from } 100 \% \\
\text { p PM and group } \\
\text { p PM and group }\end{array}$ & & & & \\
\hline
\end{tabular}




\section{Sedation In ENDOBRonchial Ultrasound-Guided TBNA}

number of sampled lymph nodes of EBUS-TBNA were higher in subjects undergoing deep sedation.

A deep sedation is required to facilitate the passage of the vocal cords and to inhibit airway protective reflexes for a smooth bronchoscopy. When a bronchoscope obstructs the airway, it will cause ventilation difficulty and affect both oxygenation and ventilation negatively. Furthermore, sedation depresses respiratory drive and can contribute to disruption of oxygenation and ventilation. ${ }^{9}$

We applied deep sedation using safe and short-acting agents in subjects, thereby protecting spontaneous breathing. Although beginning $\mathrm{S}_{\mathrm{pO}_{2}}$ was different among the groups, it wasn't clinically meaningful. $\mathrm{S}_{\mathrm{pO}_{2}}$ measurements during EBUS-TBNA showed adequate oxygenation. Especially when propofol is combined with opioids, the dosage of propofol may be limited due to respiratory depression and hypotension..$^{5,7,8}$ It was reported that ketamine can be used safely and effectively to avoid these problems in children during fiberoptic bronchoscopy. ${ }^{8}$ However, ketamine use is limited due to nausea, agitation during recovery, and longer recovery time. ${ }^{22}$ Ketofol (1:1 combination of propofol and ketamine) allows usage of lower doses of each agent and fewer side effects. ${ }^{23}$

Studies evaluating the use of ketamine-propofol combination for interventional procedures in emergency rooms ${ }^{12-15}$ or in other departments ${ }^{24-26}$ are common. It was reported that this combination can be used in painful procedures, providing adequate sedation and analgesia. ${ }^{12,13}$ Nejati et al ${ }^{12}$ concluded that the combination of ketaminepropofol causes less oxygen desaturation and deeper sedation and analgesia compared with the combination of midazolam-fentanyl for painful emergency procedures. In addition, they reported that it is essential to provide proper monitoring and cardiopulmonary support as in all sedation and analgesia protocols to avoid adverse events. Ketofol provided shorter recovery time without side effect and more stable hemodynamics than ketamine for anesthesia in electroconvulsive treatment. ${ }^{15}$ Andolfatto et al ${ }^{14}$ reported that ketofol did not reduce respiratory side effects compared with propofol alone. Although ketofol and propofol had similar efficacy and acting times, ketofol provided more balanced deep sedation in that study. ${ }^{14}$ In a retrospective study including 979 subjects, the administration frequency of 2 or more sedative agents in combination was 93\% in the emergency room. ${ }^{27}$ This percentage was found to be $90 \%$ in our study.

In the present study, predominant complications were increase in blood pressure (14\%) and desaturation (7\%). However, they were temporary and responsive to treatment. The rate of these complications was higher in females. Transbronchial biopsy is associated with an increased risk of pneumothorax compared with EBUSTBNA. ${ }^{28}$ EBUS-TBNA procedures were performed without transbronchial biopsy in our center. Pneumothorax and bleeding, rare and major complications of EBUS-TBNA, were found in only one subject for each.

In a trial by Campbell et al, ${ }^{27}$ it was suggested that sedation- and analgesia-related adverse effects were rare in emergency departments, and the incidence of desaturation was $1 \%$.

In another study, it was reported that desaturation was an infrequent complication of deep sedation during endoscopic procedures, and the incidence was $4 \% .{ }^{29} \mathrm{~A}$ slight increase in desaturation incidence may be due to interventional bronchoscopy under deep sedation in our research.

Five subjects with desaturation, requiring mask ventilation or endotracheal intubation, were in groups that were administered midazolam. The PFT and baseline $\mathrm{S}_{\mathrm{pO}_{2}}$ level were lower in subjects who developed desaturation. Baseline $\mathrm{S}_{\mathrm{pO}_{2}}$ level was found as the sole factor for the development of desaturation.

In a study comparing propofol-ketamine to alfentanylpropofol sedation, systolic arterial pressure and HR increased during the procedure in both groups compared with values immediately before starting fiberoptic bronchoscopy. ${ }^{7}$ Here, baseline hemodynamic measurements were similar and normal in all groups. Beginning from the second measurement, obtained following the passage of the bronchoscope through vocal cords, blood pressures were higher throughout the procedure in groups with ketamine. Baseline systolic arterial pressure was the most significant factor associated with the development of high blood pressure during the procedure. The incidence of high blood pressure also increased during the procedure in subjects with hypertension. The occurrence of high blood pressure was approximately 5 times higher in group PK compared with group P. Likelihood of high blood pressure development was higher in groups with ketamine. This increase might also be due to decreased propofol consumption in these groups.

El Chafic et $\mathrm{al}^{29}$ reported that a decrease in systolic arterial pressure during sedation for endoscopy was more common in male patients, as well as in patients who received midazolam and fentanyl. Campbell et al ${ }^{27}$ observed that the combination of propofol-fentanyl mostly in males and combination of midazolam-fentanyl mostly in females were used. They also found that the midazolam-fentanyl combination was used more in patients over $65 \mathrm{y}$ of age. In our study, we determined that the number of male subjects was higher in the propofol-ketamine group than in the propofol-ketamine-midazolam group. Furthermore, in groups receiving ketamine, the average age, percentage of ASA III subjects, and incidence of hypertension and coronary artery disease were lower than other groups. We observed that preference of sedative agents and combinations could depend on gender, age, physical status, and comorbidity. 


\section{Sedation In ENDOBRonchial Ultrasound-Guided TBNA}

It was reported that infusion of propofol-ketamine combination resulted in longer recovery time $(42.9 \pm 18.7 \mathrm{~min})$ compared with propofol-remifentanil combination during deep sedation for dental procedures. ${ }^{30}$ In our study, shorter recovery times might be due to intermittent and titrated bolus injection of sedative agents. Recovery time was the fastest in the propofol-only group, whereas it was the longest in the propofol-midazolam-ketamine group. In addition, it was similar in 2-agent combinations.

Whereas there was an inverse relation between recovery time and age, higher duration of EBUS-TBNA, baseline mean arterial pressure, and HR increased the recovery time in our study. Because there was no significant relationship between recovery time and total agent consumption, this interaction might be related to discrepancy of anesthetic distribution.

Using a mean of $28 \mathrm{mg}$ of propofol, Hwang et $\mathrm{al}^{7}$ provided sufficient sedation levels for fiberoptic bronchoscopy in a propofol-ketamine group. Similarly, we used approximately $25 \mathrm{mg}$ of propofol during induction when we combined the drug with ketamine. Presence of ketamine in combinations decreased total propofol consumption by approximately $50 \%$ (mean $55 \mathrm{mg}$ ). We observed that total doses in our groups $\mathrm{P}$ and $\mathrm{PK}$ were similar to ones in studies reported by Andolfotto et $\mathrm{al}^{14}$ and Yalcin et al ${ }^{15}$ Presence of ketamine in our combinations also reduced midazolam doses. Although the propofol dose in combinations was lower, we observed that both propofol by itself and propofol in combination with midazolam and/or ketamine provided similar and safe deep sedation for EBUS-TBNA. This observation may be supported by the comparable number of injections in these groups.

Patient satisfaction was quite high following an EBUSTBNA procedure under sedation among bronchoscopic procedures. ${ }^{19}$ In our study, the percentage of subjects who indicated that they would have another EBUS-TBNA procedure under sedation was $100 \%$ in group PM, $>99 \%$ in group PK, $95 \%$ in group PKM, and $100 \%$ in group P. This percentage was reported as $98 \%$ in the study performed by Steinfort et al. ${ }^{5}$ In that report, satisfaction was also determined by subject's willingness to return for the procedure in the future. They used the 5-point Likert scale to assess tolerance of EBUS. ${ }^{5}$ A similar 5-point scale has been previously used to evaluate tolerance of bronchoscopy. ${ }^{31} \mathrm{We}$ thought that high patient satisfaction might be related to deep sedation.

It was thought that unwanted respiratory side effects were more frequent during repeated bolus injections. ${ }^{9}$ However, we think that if the anesthetic agent is administered as bolus injections during EBUS, respiratory side effects can be reduced by close hemodynamic monitoring and careful dose titration. Despite the fact that coughing is frequent during EBUS-TBNA, we didn't encounter cough- ing that necessitated termination of the procedure in our study.

Previously, it has been shown that transcutaneous $\mathrm{P}_{\mathrm{CO}_{2}}$ is an important value that should be used in the assessment of various sedation agents during bronchoscopy. ${ }^{32}$ Absence of transcutaneous $\mathrm{P}_{\mathrm{CO}_{2}}$ monitoring during the procedure is considered as the limitation of the current report. In the present sedated subjects, bispectral index monitoring was not used to measure depth of sedation. Instead, sedation depth was assessed qualitatively. Recently, Fruchter et al ${ }^{33}$ proposed that bispectral index monitoring during propofol sedation in procedures with a short duration does not result in a safer level of sedation; therefore, its routine use should not be considered.

A previous prospective multicenter study suggested that escalations in level of care were more likely to be required in older patients, in-patients, and patients who received deep sedation or general anesthesia when complications occurred. ${ }^{28}$ We think that experienced medical staff is required during deep sedation for EBUS-TBNA to prevent cardiopulmonary depression due to sedatives. Additionally, the procedure should be performed in a department that could provide immediate cardiopulmonary resuscitation if necessary. Furthermore, operating room facilities and additional personnel could be required during deep sedation.

\section{Conclusions}

Independent from sedative agent, deep sedation, providing high level patient satisfaction, hemodynamic and respiratory stability, and faster recovery time, was safe and effective in subjects undergoing EBUS-TBNA. There was no relationship between presence of complications and age, ASA classification, PFTs, presence of comorbidities, EBUS-TBNA time, and the number of sedative agent injections during the procedure. Desaturation and increased blood pressure were temporary, responsive to treatment, and more frequent complications. The incidence of developing high blood pressure during the procedure was higher in groups receiving ketamine. Presence of ketamine in combination reduced the requirement for midazolam and propofol. Recovery was the fastest in group $\mathrm{P}$, and highest in group PKM. There was no relation between recovery time and gender, ASA classification, PFTs, total dose of anesthetics, and presence of chronic disease.

\section{REFERENCES}

1. Yasufuku K, Chiyo M, Koh E, Moriya Y, Iyoda A, Sekine Y, et al. Endobronchial ultrasound guided transbronchial needle aspiration for staging of lung cancer. Lung Cancer 2005;50(3):347-354.

2. Sayar A, Citak N, Metin M, Turna A, Pekçolaklar A, Kök A, et al. Comparison of video-assisted mediastinoscopy and video-assisted 


\section{Sedation In ENDOBRonchial Ultrasound-Guided TBNA}

mediastinoscopic lymphadenectomy for lung cancer. Gen Thorac Cardiovasc Surg 2011;59(12):793-798.

3. Yasufuku K, Pierre A, Darling G, de Perrot M, Waddell T, Johnston $\mathrm{M}$, et al. A prospective controlled trial of endobronchial ultrasoundguided transbronchial needle aspiration compared with mediastinoscopy for mediastinal lymph node staging of lung cancer. J Thorac Cardiovasc Surg 2011;142(6):1393-1400.

4. Gu P, Zhao YZ, Jiang LY, Zhang W, Xin Y, Han BH. Endobronchial ultrasound-guided transbronchial needle aspiration for staging of lung cancer: a systematic review and meta-analysis. Eur J Cancer 2009; 45(8):1389-1396

5. Steinfort DP, Irving LB. Patient satisfaction during endobronchial ultrasound-guided transbronchial needle aspiration performed under conscious sedation. Respir Care 2010;55(6):702-706.

6. Gonzalez R, De-La-Rosa-Ramirez I, Maldonado-Hernandez A, Dominguez-Cherit G. Should patients undergoing a bronchoscopy be sedated? Acta Anaesthesiol Scand 2003;47(4):411-415.

7. Hwang J, Jeon Y, Park HP, Lim YJ, Oh YS. Comparison of alfetanil and ketamine in combination with propofol for patient-controlled sedation during fiberoptic bronchoscopy. Acta Anaesthesiol Scand 2005;49(9):1334-1338.

8. Berkenbosch JW, Graff GR, Stark JM. Safety and efficacy of ketamine sedation for infant flexible fiberoptic bronchoscopy. Chest 2004;125(3):1132-1137.

9. Berkenbosch JW, Graff GR, Stark JM, Ner Z, Tobias JD. Use of a remifentanil-propofol mixture for pediatric flexible fiberoptic bronchoscopy sedation. Paediatr Anaesth 2004;14(11):941-946.

10. Camu F, Vanlersberghe C. Pharmacology of systemic analgesics. Best Pract Res Clin Anaesthesiol 2002;16(4):475-488.

11. Mortero RF, Clark LD, Tolan MM, Metz RJ, Tsueda K, Sheppard RA. The effects of small-dose ketamine on propofol sedation: respiration, postoperative mood, perception, cognition, and pain. Anesth Analg 2001;92(6):1465-1469.

12. Nejati A, Moharari RS, Ashraf H, Labaf A, Golshani K. Ketamine/propofol versus midazolam/fentanyl for procedural sedation and analgesia in the emergency department: a randomized, prospective, double-blind trial. Acad Emerg Med 2011;18(8):800-806.

13. Willman EV, Andolfatto G. A prospective evaluation of "ketofol" (ketamine/propofol combination) for procedural sedation and analgesia in the emergency department. Ann Emerg Med 2007;49(1):2330.

14. Andolfatto G, Abu-Laban RB, Zed PJ, Staniforth SM, Stackhouse S, Moadebi S, Willman E. Ketamine-propofol combination (ketofol) versus propofol alone for emergency department procedural sedation and analgesia: a randomized double-blind trial. Ann Emerg Med 2012;59(6):504-512.

15. Yalcin S, Aydoğan H, Selek S, Kucuk A, Yuce HH, Karababa F, Bilgic T. Ketofol in electroconvulsive therapy anesthesia: two stones for one bird. J Anesth 2012;26(4):562-567.

16. Dal T, Sazak H, Tunç M, Şahin Ş, Yılmaz A. A comparison of ketamine-midazolam and ketamine-propofol combinations used for sedation in the endobronchial ultrasound-guided transbronchial needle aspiration: a prospective, single-blind, randomized study. J Thorac Dis 2014;6(6):742-751.

17. Ramsay MA, Savege TM, Simpson BR, Goodwin R. Controlled sedation with alphaxalone-alphadolone. BMJ 1974;22(2):656-659.
18. Aldrete JA. The post-anesthesia recovery score revisited. J Clin Anesth 1995;7(1):89-91.

19. Chandra S, Nehra M, Agarwal D, Mohan A. Diagnostic accuracy of endobronchial ultrasound-guided transbronchial needle biopsy in mediastinal lymphadenopathy: a systematic review and meta-analysis. Respir Care 2012;57(3):384-391.

20. Tremblay A, Stather DR, Maceachern P, Khalil M, Field SK. A randomized controlled trial of standard vs endobronchial ultrasonography-guided transbronchial needle aspiration in patients with suspected sarcoidosis. Chest 2009;136(2):340-346.

21. Yarmus LB, Akulian JA, Gilbert C, Mathai SC, Sathiyamoorthy S, Sahetya $\mathrm{S}$, et al. Comparison of moderate versus deep sedation for endobronchial ultrasound transbronchial needle aspiration. Ann Am Thorac Soc 2013;10(2):121-126.

22. Strayer RJ, Nelson LS. Adverse events associated with ketamine for procedural sedation in adults. Am J Emerg Med 2008;26(9):9851028.

23. Bowdle TA, Radant AD, Cowley DS, Kharasch ED, Strassman RJ, Roy-Byrne PP. Psychedelic effects of ketamine in healthy volunteers: relationship to steady-state plasma concentrations. Anesthesiology 1998;88(1):82-88.

24. Akin A, Esmaoglu A, Guler G, Demircioglu R, Narin N, Boyaci A Propofol and propofol-ketamine in pediatric patients undergoing cardiac catheterization. Pediatr Cardiol 2005;26(5):553-557.

25. Akin A, Guler G, Esmaoglu A, Bedirli N, Boyaci A. A comparison of fentanyl-propofol with a ketamine-propofol combination for sedation during endometrial biopsy. J Clin Anesth 2005;17(3):187190

26. Frey K, Sukhani R, Pawlowski J, Pappas AL, Mikat-Stevens M, Slogoff S. Propofol versus propofol-ketamine sedation for retrobulbar nerve block: comparison of sedation quality, intraocular pressure changes, and recovery profiles. Anesth Analg 1999;89(2):317-321.

27. Campbell SG, Magee KD, Kovacs GJ, Petrie DA, Tallon JM, McKinley $\mathrm{R}$, et al. Procedural sedation and analgesia in a Canadian adult tertiary care emergency department: a case series. Can J Emerg Med 2006;8(2):85-93

28. Eapen GA, Shah AM, Lei X, Jimenez CA, Morice RC, Yarmus L, et al. Complications, consequences, and practice patterns of endobronchial ultrasound-guided transbronchial needle aspiration: results of the AQuIRE Registry. Chest 2013;143(4):1044-1053.

29. El Chafic AH, Eckert G, Rex DK. Prospective description of coughing, hemodynamic changes, and oxygen desaturation during endoscopic sedation. Dig Dis Sci 2012;57(7):1899-1907.

30. Kramer KJ, Ganzberg S, Prior S, Rashid RG. Comparison of propofol-remifentanil versus propofol-ketamine deep sedation for third molar surgery. Anesth Prog 2012;59(3):107-117.

31. Lechtzin N, Rubin HR, White P Jr, Jenckes M, Diette GB. Patient satisfaction with bronchoscopy. Am J Respir Crit Care Med 2002; 166(10):1326-1331

32. Carmi U, Kramer MR, Zemtzov D, Rosengarten D, Fruchter O. Propofol safety in bronchoscopy: prospective randomized trial using transcutaneous carbon dioxide tension monitoring. Respiration 2011; 82(6):515-521

33. Fruchter O, Tirosh M, Carmi U, Rosengarten D, Kramer MR. Prospective randomized trial of bispectral index monitoring of sedation depth during flexible bronchoscopy. Respiration 2014;87(5):388-393. 